\title{
La Biblioteca Acampada Sol
}

\author{
Julio Santillán-Aldana
}

Grupo Biblios

ENTREVISTA

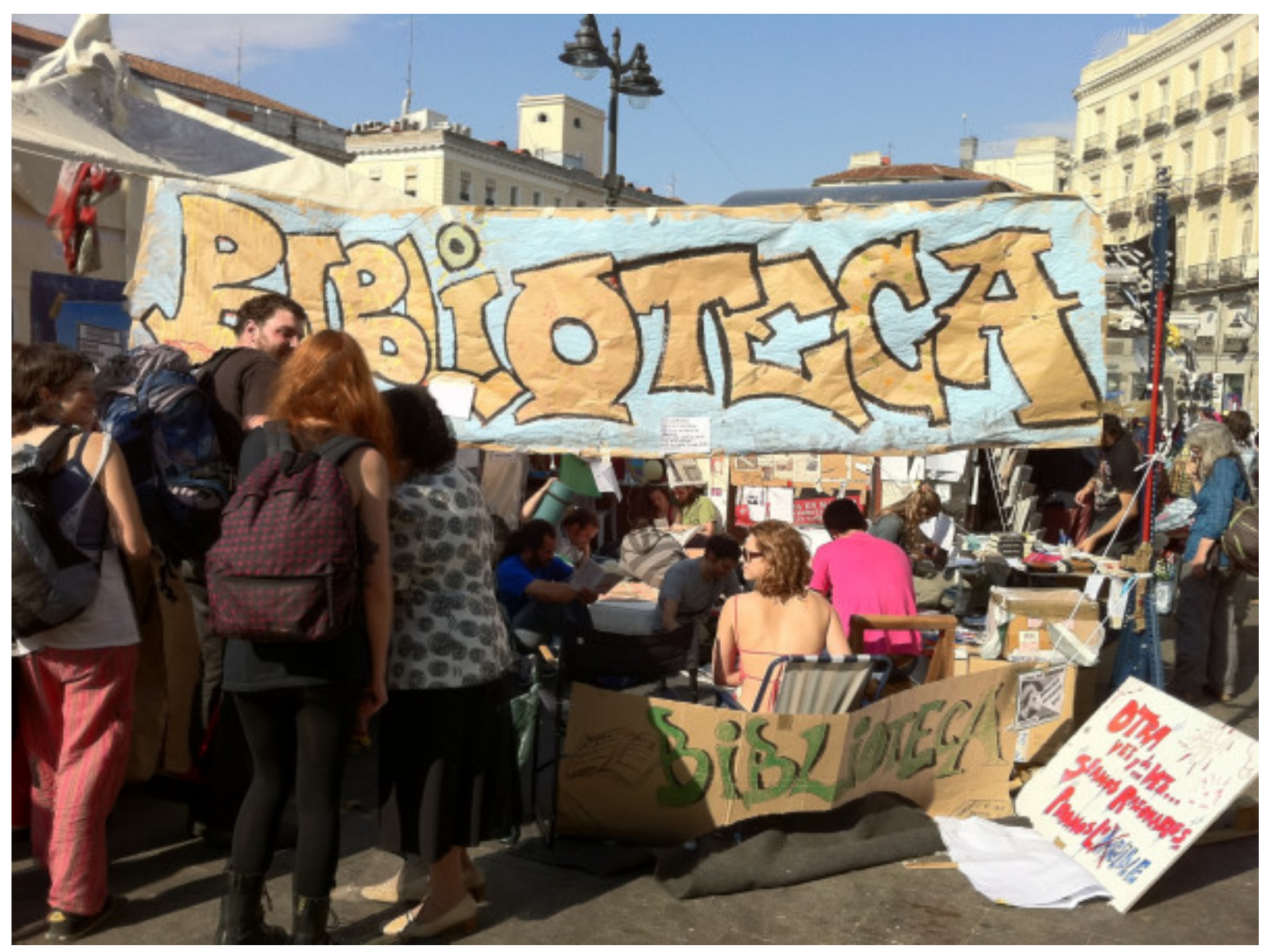

\section{Sol Camping Library}

Tras la espontánea conformación del Movimiento Ciudadano de los Indignados en España el 15 de mayo último, conocido en adelante como 15-M, se han sucedido diversos hechos emblemáticos desde los manifestantes. Así el campamento masivo en la Puerta del Sol de Madrid y su intensa actividad colectiva han favorecido la conformación de una gran biblioteca popular denominada Bibliosol.

Motivados por este hecho tan particular y significativo para el ámbito bibliotecario internacional, buscamos conversar a la distancia y de forma colectiva con los bibliotecarios voluntarios de Bibliosol, quienes compartieron con nosotros sus reflexiones sobre varios temas de fondo de esta biblioteca popular. 


\section{El derecho de acceso a la cultura y la información}

Biblios (B): Mientras que en el Sur, América Latina, diversas naciones van asumiendo el derecho a la información de las personas, y en consecuencia fomentando los servicios de información pública, y con ello las bibliotecas; en el Norte, Estados Unidos y Europa, este derecho se va debilitando, haciendo incluso insostenible algunas bibliotecas públicas emblemáticas. ¿Qué está fallando, en el llamado primer mundo, en torno al derecho de acceso a la cultura y a la información?

Bibliosol (BS): En primer lugar, hay que decir que la situación de esta cuestión dentro de lo que se denomina primer mundo es desigual y diversa, dependiendo de los países o áreas en las que nos fijemos (el mundo anglosajón Reino Unido y Estados Unidos principalmente-, los países escandinavos o el resto de Europa occidental), creemos que estas tres áreas o regiones definen estados y tendencias diferentes respecto a esta cuestión. Sin embargo sí hallamos rasgos comunes en todas ellas y en todo el primer mundo. Nos parece interesante hacer notar o recordar que en la era de la información, una gran parte (o casi toda) de esta información no es conocimiento.

Esto es de gran importancia porque a veces el acceso a la cultura y el acceso a la información parecen verse contrapuestos o resultar en cierto modo incompatibles. Veamos como Internet y los medios de comunicación de masas, que copan los espacios para la distribución de la información en nuestro mundo globalizado, no están investidos de cultura o conocimiento, como no sea de lo que podemos llamar industria cultural o cultura de masas. Esto es importante porque invisibiliza el mundo de la cultura y el conocimiento, restringe su difusión, y con ello degrada el derecho de acceso a la cultura y dificulta su ejercicio.

Además de esto, que es en gran parte un problema de difusión, tenemos que mencionar que la apuesta por un modelo de economía neoliberal, con raíces en los años ochenta y recrudecida en los momentos que vivimos, está minando el derecho de acceso a la cultura y poniéndolo en peligro como ocurre con otros derechos sociales. Y es que la garantía y el ejercicio de estos derechos no resultan muy compatibles con los principios de rentabilidad y competitividad que nuestros gobernantes empiezan a asumir a golpe de imposición venida de otras instancias ajenas a los Estados y supranacionales, de naturaleza económica o financiera.

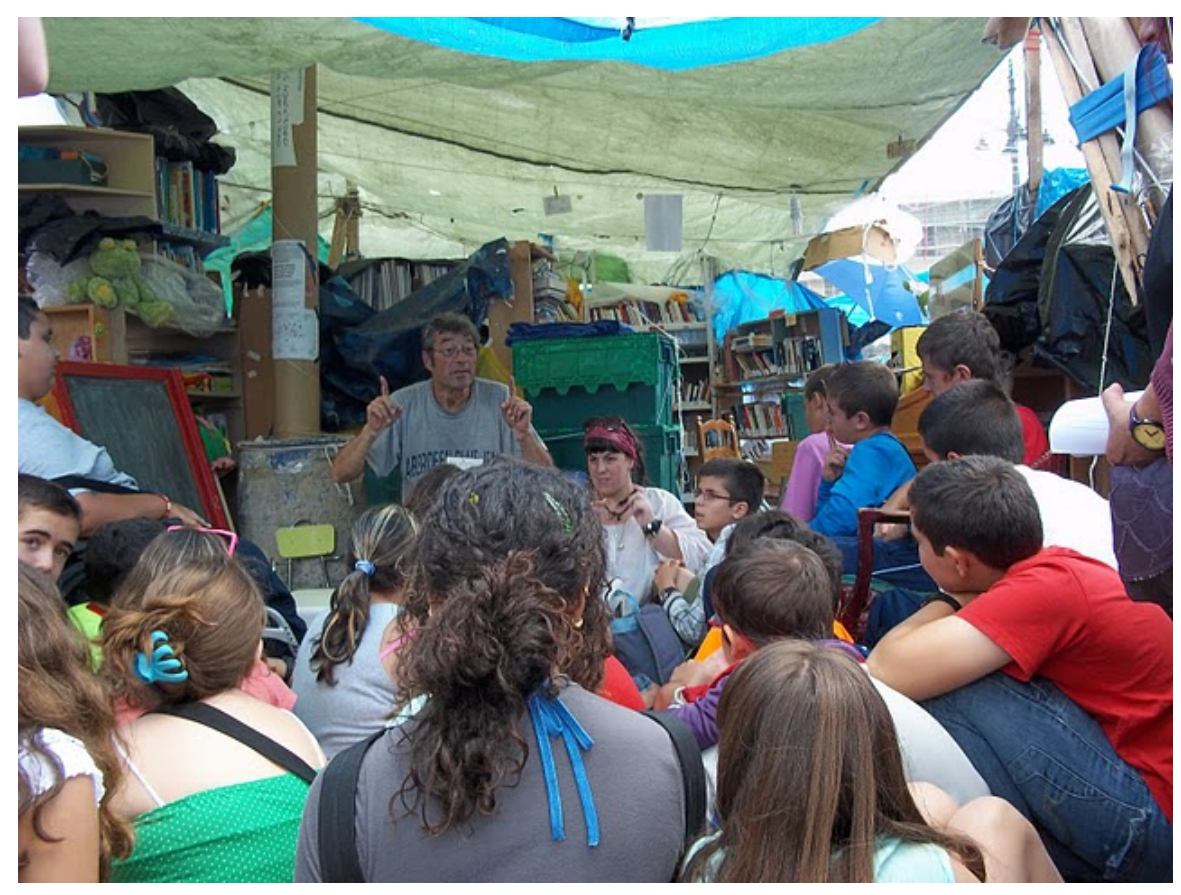

Biblioteca Infantil de Bibliosol. Madrid, España 


\title{
El futuro incierto de las bibliotecas públicas
}

\begin{abstract}
B: En el Manifiesto Bibliosol se sustentan la importancia de la biblioteca pública, como espacio que contribuye al ejercicio del derecho a la información y que promueve la democracia. ¿Consideran ustedes que las bibliotecas públicas de su realidad se encuentran coaptadas por razones opuestas al derecho de la información?
\end{abstract}

BS: En relación con lo ya dicho, uno de los principales problemas de que adolecen actualmente las bibliotecas públicas es la creciente falta de medios materiales y humanos. La austeridad y la reducción del gasto afectan a este servicio público, como ya decía, lo hace con otros, como los servicios sanitarios.

Parece que la tendencia, para la cual además no habría alternativa posible según gobernantes e instituciones, es a una privatización "encubierta" de todos estos servicios. El proceso empieza por recortes, sigue con la subcontratación al sector privado de parte de estos servicios o de su gestión, y acaba por una privatización completa de los servicios públicos. Esta es la principal amenaza que ahora se cierne sobre las bibliotecas públicas.

\section{Bibliotecas populares, una expresión democrática}

B: César Vallejo escribió la frase "Todo acto o voz genial viene del pueblo y va hacia él" ¿Consideran ustedes que algunos servicios, como es el caso de las bibliotecas, deben ser cautelados y administrados directamente por la comunidades? ¿Debemos retornar a las llamadas bibliotecas populares?

Es claro que esto constituiría la puesta en práctica del principio democrático. Sería también un ejemplo y un ejercicio de democracia participativa, algo que admiramos, reclamamos y creemos posible. Pero es que además esta idea de tutela y gestión de las bibliotecas o de otros servicios públicos por las comunidades, se convierte en una necesidad y una urgencia cuando la Administración y las instituciones han dejado de trabajar por nuestros intereses, y lo hacen, por contra, para otros intereses que resultan opuestos las más de las veces a los de la ciudadanía. En la legislación española -que no olvidemos es la expresión de la voluntad y la soberanía popular en una democracia- se recoge esta función de garante del acceso a la cultura, la información y el conocimiento para la biblioteca pública. Cuando nuestros poderes públicos incumplen lo que de nuestra voluntad se supone ha salido, se hace necesario e interesante abrir nuevos espacios, como serían las bibliotecas populares, en un ensayo y una práctica de democratización de la sociedad y difusión de la cultura.

\section{Pensamientos para el mañana}

B: Muchos niños y jóvenes van visitando la Biblioteca Acampada Sol ¿Qué mensaje les gustaría a ustedes que ellos se lleven de esta experiencia?

A los más jóvenes les diríamos que abrir un libro nos enseña que las cosas no son siempre como nos cuentan o nos han contado. Que abrir un libro nos enseña a pensar, a imaginar, a experimentar, a sentir, a soñar, también a vivir. Que leer un libro es una experiencia que puede transformarte, hacerte mejor, desde luego mucho más que un programa de televisión. Queremos y creemos en fomentar el pensamiento crítico, nos dicen que las cosas no pueden ser de otra manera porque hemos perdido este pensamiento. El saber y la cultura son un arma, un arma no violenta, un arma que sólo hace daño a quien vive sobre dogmas y pretende imponer a los demás su visión del mundo.

Nos gustaría que los más jóvenes adquiriesen esta arma. Que aprendiesen el potencial transformador y emancipador que ésta tiene, tanto a nivel individual como colectivo, haciéndoles capaces de cambiarse a sí mismos y de contribuir a cambiar la sociedad. Ésta ha sido nuestra razón de ser en la Puerta del Sol de Madrid. Creemos firmemente en los principios que nos han movido: criticismo, pacifismo, respeto, solidaridad, voluntad de cambio; y queremos transmitirlos y legarlos a las generaciones más jóvenes, entendiendo que sin la cultura la lucha por el cambio no es posible. 


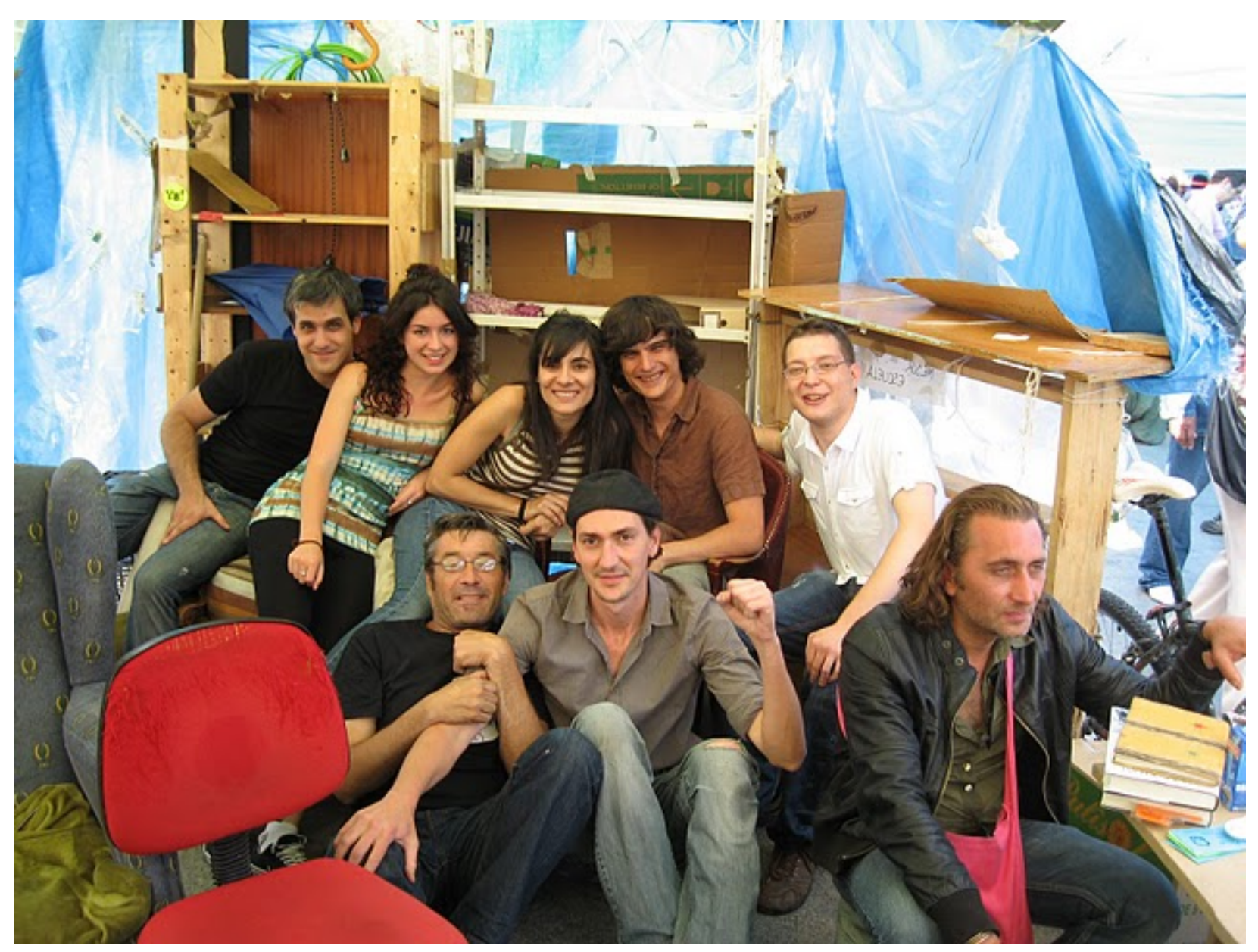

Voluntariado Bibliosol. Madrid, España

\section{Mayor información}

Bibliosol. (2011). Biblioteca Acampada Sol. [En línea]. Disponible en < $\underline{\text { http://bibliosol.wordpress.com> }}$

Manifiesto Bibliosol. (2011). Plataforma por la Creación del Colegio Oficial de Archiveros, Bibliotecarios y Documentalistas de Madrid. [En línea]. Disponible en <http://coabdm.wordpress.com/2011/06/02/manifiesto-de-la-biblioteca-indignada-bibliosol>

\section{(oc) EY-NC-ND}

This work is licensed under a Creative Commons

Attribution-Noncommercial-No Derivative Works 3.0 United States License.

\section{UILIS D-Sunt}

This journal is published by the University Library System of the University of Pittsburgh as part of its D-Scribe Digital Publishing Program and is cosponsored by the University of Pittsburgh Press. 